\title{
Has a Decade of ComputerisationMade a Difference in School Management?
}

\author{
P. Wild, D. Smith and J. Walker
}

Department of Education, Laughborough University, Loughborough, Leicestershire, VKLE11 $3 T U$

Key words: School Information Systems, Longitudinal Study, Effectiveness, Usability

Abstract: The paper describes a longitudinal study to assess the effectiveness and usability of a computerised school management and administration system used in the majority of secondary schools in the UK. Case studies were made in 1990 and 1996, and in 1999 a full-scale survey was carried out in secondary schools in England. From the survey results we attempted to evaluate how successful was the system in use, and how its role has changed.

\section{INTRODUCTION}

Schools in the United Kingdom have experienced much organisational change over the last decade following the Education Reform Act in 1988 and the devolution of financial and managerial responsibility out of central government to schools. The government made available $£ 325$ million over three years to provide computer systems to accommodate this extra managerial load and use of these computerised systems has become increasingly important in the management of educational institutions (Visscher, 1996). Government funding was initially at $70 \%$, with Local Education Authorities (LEAs) providing the balance. This decreased after two years to $60 \%$, so there was a strong incentive to take up funding early on in the process. The majority of LEAs took up funding in the first year (1989). As a result many LEAs implemented new IT systems at a rapid pace. Previous studies have shown that these installations were assessed from an accountancy perspective at the expense of assessment of system usability 
and user acceptance (Wild et al., 1992). Independent schools did not receive any funding at all from government sources.

One typical software system for computerised school management and administration used at this time was SIMS (Capita Software) which was promoted by several LEAs and already dominated the market in the early 1990's. SIMS (School Information Management System) was targeted as the system to be investigated at the start of the study when most educational establishments had only been running the software for a maximum of one year. Ten years on it is now the most widely used software of this type in England.

This paper is an investigation of how the use of this particular computer system has developed over the last decade with particular reference to its changing role as a management tool over the period. It seeks to give an overview of the situation only. A more detailed analysis of the collected data will follow at a later date.

Computerised Information Systems have been used in schools for several years, but, as with many organisational tools, it is questionable whether these systems are being used completely effectively. Studies in the Netherlands (Visscher \& Bloemen, 1999) have shown that a considerable variance exists in the type and extent of Schools Information System usage. They suggest that despite the systems having evolved from a highly clerical emphasis to one supporting the activities of school managers and thereby meeting the apparent demands of the users, the wide variance in user requirements means that not all end users find them useful.

We consider that a successful computerised information system is one in which the integration of data and the related contextual and organisational information is complete. In order to achieve this it is necessary to have a comprehensive data flow underpinned by an appropriate (in education) pedagogical, organisational and managerial structure in place in the institution in question. To determine with what success this is happening in the UK, a longitudinal study was set up to assess the effectiveness and usability of SIMS as a computerised school management and administration tool. This paper describes our initial work to provide an framework on which to base assessment of how the dataflow is affected by the introduction and use of the computerised system and how this in turn has affected managerial styles and decision making within the organisation.

\section{METHODOLOGY}

Questionnaires were sent out to schools in England that used the SIMS information system. Sample points for the study were in 1990, 1996 and 
1999 and data was obtained from questionnaires. In the first case study (1990), sixteen schools were sent two questionnaires each, one for primary (direct) and one for secondary (indirect) users. Subsequently in 1996, 31 sets of four questionnaires were returned from a sample of 78 schools and in 1999 three questionnaires were sent to each of approximately $25 \%$ of all secondary schools in England (968) with a return rate of approximately $45 \%$. The sample of schools for this latter part of the study was taken from Local Education Authorities that were known to promote the use of SIMS, thus ensuring a high number of SIMS users responded. No attempt was made to engage the same respondent population throughout the study since this was not considered practical over such a long period of time. Data was thus obtained for a period from initial installation of SIMS (1989) over a decade of use up to 1999.

Questionnaires were sent to people who had various different roles within each school in the surveys. In the first study questionnaires were sent to direct and indirect users of SIMS. In the second survey they were sent to the Head, the SIMS Administrator, a teacher and a member of the clerical staff. In the final survey, the Head, the SIMS Administrator and a member of the clerical staffwere questioned. The Head's questionnaire in both later studies included an additional section on management tasks and responsibilities relating to the use of SIMS, otherwise all questions were the same for each group of respondents.

Questions solicited information on various factors including the users' computing background and SIMS knowledge, training and support, system functionality employed, system usability and its effect on their jobs. In addition, Heads were questioned on how they used the system in support of managerial decisions. Respondents were asked in detail for their views on the system usability and were able to contribute their own comments at the end the questionnaire.

\subsection{The SIMS system}

SIMS is a modular system comprising various different elements. It is an integrated system in that once entered, core data is available to other modules. The producers of SIMS have tried to address the need for schools to keep accurate records whilst handling student and staff information in many different contexts, from class lists to cover rotas.

The number of modules has increased, diversified and modified since the start of our study, which coincided with the introduction of SIMS into many schools. In 1990 it was a relatively new software system and few people had much experience of using it. The earlier questionnaires reflected this in their more limited scope. 


\subsubsection{A brief description of SIMS modules}

The current suite of modules has evolved in breadth and functionality over a period of ten years. Whilst the original modules were all DOS based, most are now available in Windows versions as well. New modules produced in the last six years are exclusively the Windows versions. The entire system is networkable and runs in either Novell or Microsoft NT environments. A degree of flexible but not cooperative working is allowed in the system in that certain modules (e.g. Timetabling, SENCO and Assessment Manager) can be set up as satellite systems. Thus work can proceed away from the main system (say a Deputy Head working on the timetable at home), whilst locking affected areas to prevent data editing and without affecting the rest of the system until subsequent data import from the satellite system.

The following descriptions refer to the SIMS schools suite of modules. A system designed for LEA use (SIMS EMS) holding data such as personnel records, site details, student placements and governor records links with the school system.

Use is made of alternative input devices, notably OMR (Examinations, Attendance, Options, Analyst, Assessment Suite), barcode readers (Library, Options) and links with third party software which use swipe card or remote radio linked keyboards for attendance data.

File export is possible from most modules and report generators to external packages such as spreadsheets, databases and word processors. Import of data, saved from other SIMS implementations (e.g. primary to secondary schools) is not well developed and in most cases impossible from the front end of the system.

Briefly, the current range of main modules is as follows:

- Alert Manager: Monitors data in the SIMS system and reports when critical criteria have been met. This might be used to monitor attendance records for a year group or of individual pupils or report when a department in school exceeds $80 \%$ of budget expenditure. Staffare able to set their own 'trigger points' and will be automatically notified when these are met.

- Analyst: Collates, analyses and presents results across a range of userdefined reviews and surveys such as opinion polls, curriculum audits and curriculum mapping. Presents results in tabular or graphical formats with a choice of filters.

- Assessment Suite: This suite consists of three modules that monitor and analyse pupil performance.

Assessment Manager provides support for recording pupil marks, grades and other scores to meet school requirements for internal 
and National Curriculum purposes. National curriculum criteria is included with the module and updated as necessary. Users can define their own 'aspects' to record data on pupils. The system offers aggregation, mean, difference and other such facilities to analyse individual or group performance. All assessments are time and date stamped allowing historical records to be built up and measured against targets. Users can define group or individual reporting sheet layouts for, say, reporting to parents.

Assessment Analysis carries out statistical calculations on data in Assessment Manager including progression lines with residuals, predictions and targets offering comparison with externally generated progression lines for comparative purposes.

Assessment Reporter contains a number of templates which allow users to customise reports containing tables, graphics and text comments linked to grades, marks or scores stored in Assessment Manager. Multiple comment banks can be developed allowing comments to be adapted to suit the target audience.

- Attendance: Designed to record attendance and allow monitoring of individuals.

- Curriculum Planner: Designed to assist with the planning of subject matter for courses taught throughout the school. Study units are built up as the basic building blocks, each containing an outline, associated activities, programmes of study being addressed, assessment forms, necessary resources and time allocation. Once the course has been planned Curriculum Planner produces textual outlines of the course, planned outcomes in terms of attainment targets, assessment techniques and resources used.

- Development Planner: This module provides a structure for creating a development plan, which defines individual projects and associated tasks with details of targets and monitoring techniques.

- Equipment Register: Assists with the maintenance of a complete inventory of equipment in the school, facilitating stock checks, health and safety checks and audit requirements for acquisition and disposal. The module has links with the Finance module for acquisition transfer and depreciation if required.

- Financial Management System (FMS): A comprehensive double entry accounts package addressing general ledger, order system, accounts payable and accounts receivable. Links are provided for integration with Central Finance systems such as County Treasurers and the module links with Personnel and STAR for staffsalaries and pupil billing.

- Budget Planning: Allows users to model budgets based on previous years or entirely new plans. Percentage increases can be applied to last 
year's budget for both income and expenditure. A number of alternative plans can be developed which vary the income, expenditure and allocations to cost centres as well as exploring the effect of staffing proposals. Once approved, the chosen plan can be exported to the FMS module.

- Key Stage Diagnostics: Produces tables and graphs enabling schools to compare their performance in Key Stage tests and teacher assessments against national benchmarks. It can be used to identify particular strengths and weaknesses within individual pupils or groups of pupils. It is possible to define sub-groups to investigate attainment against such issues as gender. Frequency graphs and item analysis allow evaluation of test performance to be carried out, including facility indices.

- MIDAS (Management Information Data Access System: (was designed to give easy access to information held across the SIMS system, including staff and student personal details, curriculum data, special needs, financial details, timetables, individual and school attendance statistics and statutory returns. It also includes event and conduct logs for students. The module was specifically designed for senior managers to access information easily without the need for detailed knowledge required to operate the all the individual modules holding the data.

- Examinations: Designed to assist with the administration of both internal and external examination seasons and sessions, the examinations modules communicate with the Examinations Boards via modem and a carrier such as British Telecom or Dialnet. Entries, amendments, forecast grades and coursework marks can be sent via modem with results, syllabus details and component details received from the Boards in the same way. OMR sheets can be printed for the input of entries and forecast grades. The module supports the nationally agreed EDI format and has comprehensive reporting and analysis functions.

- Timetabling Starting with a list of teachers, pupils, rooms and simple details of the timetable cycle (all imported from STAR) and first assists with the production of the curriculum plan. Several different plans can be constructed and costed before the actual timetabling process begins. This module has both manual and automatic scheduling routines and once the timetable is constructed students are assigned to the classes. Various printing and analysis routines are provided. Integral within the package is the Cover module which maintains details of teacher absence and assists with the business of assigning cover, notifying cover staff, maintaining a database of supply teachers and offering analysis functions.

- Options: This module facilitates the process of student options allocation, whether in a free choice or directed choice situation. Reserve 
choices can also be taken in to account. Options will advise on the numbers of classes required in each subject, the block structures and will try to optimise the class sizes in keeping with the subject and ability range. The module produces various lists and analyses and exports its data for incorporation in the timetable.

- Personnel: The Personnel module stores personal, professional and contractual information about all teaching and non-teaching school staff. The module also links with the SIMS EMS system allowing the automatic exchange of staff information changes between a school and the Local Education Authority.

- Photo Importer: Allows the import of bitmap format images from whatever source - e.g. digital camera, scanner or video camera, and then links with the STAR or Personnel modules to import student or staff photographs for use in the SIMS modules. Many school photographic services, e.g. Tempest, now offer individual bitmap images for the whole school on CD ROM as part of the annual school photograph activity.

- RepGen and RepGen Lite: RepGen (DOS) and RepGen Lite (Windows ) allow the design of individual reports from data held in the rest of the system. RepGen Lite will report across several different modules. Both modules contain pre-defined reports but users can add as many others as wished, including filters and the order of printing fields which can be stored for future use. Files can also be produced for export to other applications such as word processors or spreadsheets.

- SENCO (Special Educational Needs Code of Practice): This module was produced to help schools comply with the Code of Practice for the Identification and Assessment of students with Special Educational Needs. The module can hold SEN information on any pupil, including past and future reviews, special provisions, links with adults (e.g. educational psychologists, doctors, teachers, etc.) and Individual Education Plans. SENCO will produce a list of actions necessary in the next chosen period, automate letter production and provide status reports on outstanding correspondence.

- STAR (Students Teaching and Academic Record): is the main database of pupil records, holding personal, medical, historic, school and academic information on each pupil. Routines are provided for new intakes. End of year procedures and global editing features ease data entry. Photographs can be imported though Photo Importer and the system uses extracts of the Post Office post code database to ensure data accuracy with the entry of contact addresses. Modules such as Form 7 produce outputs for statutory returns based on the data held in STAR.

- Value Added: Used in setting targets and investigating individual and school performance based on GCSE and GCE A level data. SIMS 
collects data fromparticipating schools in August and creates benchmark statistics which can be used by schools for comparison purposes. Predicted outcomes in various subjects at A level, based on individual pupil performance at GCSE and comparison with national figures, can also beprovided.

- Visitor Log: The Visitor Log module is designed for use in the reception area in order to maintain an accurate record of visitors. It will print personalised badges (with a photograph if linked to a digital video camera), record entry and departure times, maintain records of purpose of visits, recall previous visitor details and provide analysis functions.

\section{RESULTS}

\subsection{Frequency of modules used}

In the 1999 study, the modules most commonly used varied according to the different roles of users within the organisation (Figure 1). The scale used to measure frequency of use was as follows: everyday (100\%), once a week $(80 \%)$, once a month $(60 \%)$, a few times a year $(40 \%)$, once a year $(20 \%)$, never (0\%). Some modules are used to their maximum at the $20-40 \%$ level. These include Examinations, Form 7, Photo Importer, Curriculum Planner and Curriculum Modeller, Development Planner, Analyst and Value Added. It should also be noted that most of these are recent modules and although licensing agreements vary between different LEAs most end users have to pay extra for them. 


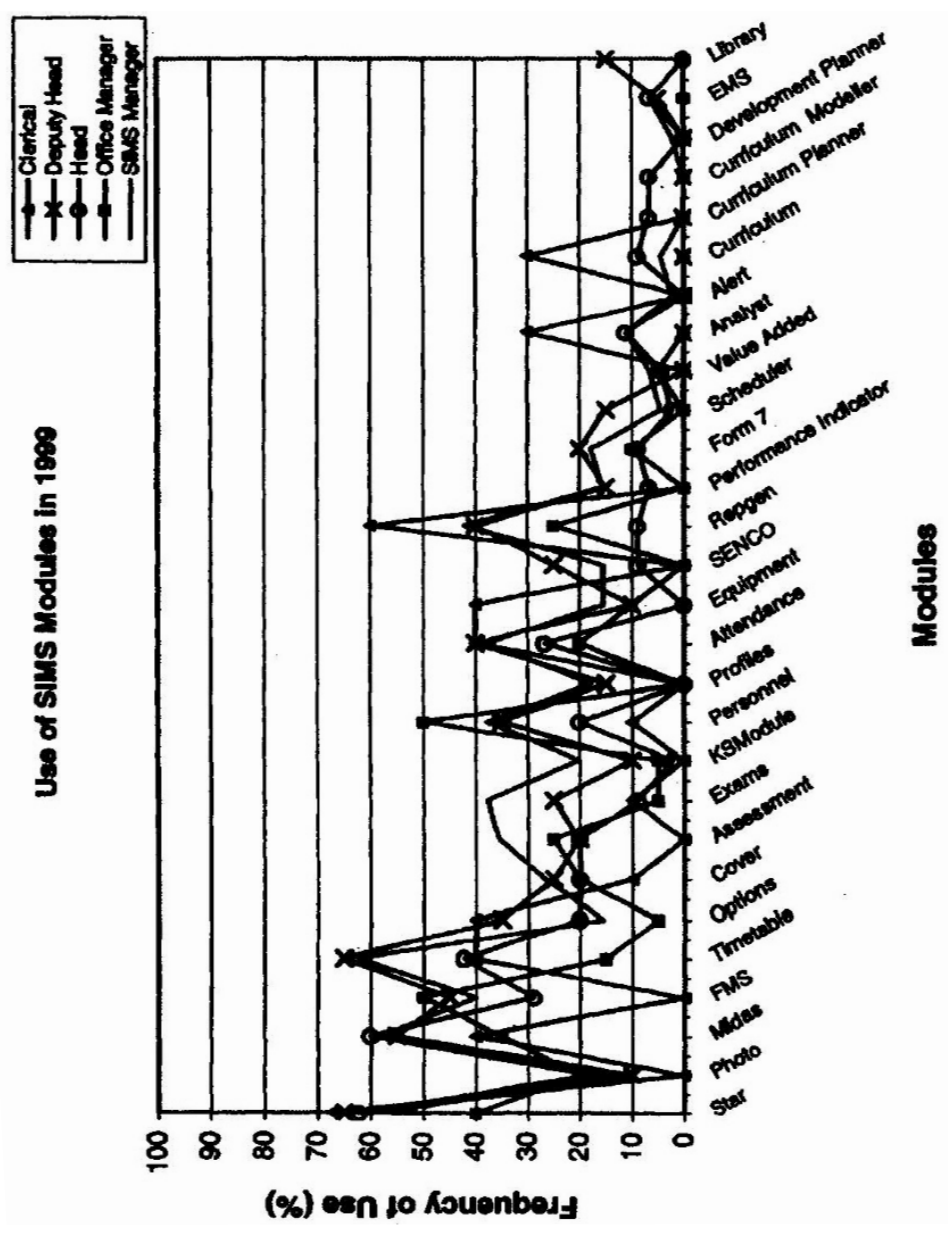

Figure 1. Frequency of SIMS module use by role (1999) 
Table 1 shows overall average use of SIMS modules.

Table 1. Frequency of module use

\begin{tabular}{|c|c|c|c|}
\hline Frequency of Use & Valid & Missing & Median* \\
\hline STAR Module & 424 & 21 & 2 \\
\hline MIDAS Module & 430 & 15 & 2 \\
\hline Timetabling Module & 424 & 21 & 3 \\
\hline RepGen Module & 432 & 13 & 3 \\
\hline FinancialManagement System Module & 423 & 22 & 4 \\
\hline Examinations Module & 423 & 22 & 4 \\
\hline Personnel Module & 425 & 20 & 4 \\
\hline Attendance Module & 419 & 26 & 4 \\
\hline Form 7 Module & 420 & 25 & 4 \\
\hline Photo Importer Module & 397 & 48 & 5 \\
\hline Options Module & 407 & 38 & 5 \\
\hline Cover Module & 413 & 32 & 5 \\
\hline Assessment Manager Module & 414 & 31 & 5 \\
\hline Key Stage Diagnostics Module & 404 & 41 & 5 \\
\hline Profiles Module & 406 & 39 & 5 \\
\hline SENCO Module & 405 & 40 & 5 \\
\hline Performance Indicator Module & 394 & 51 & 5 \\
\hline Scheduler Module & 390 & 55 & 5 \\
\hline Value Added Module & 367 & 78 & 5 \\
\hline Analyst Module & 365 & 80 & 5 \\
\hline Alert Manager Module & 369 & 76 & 5 \\
\hline Curriculum Module & 368 & 77 & 5 \\
\hline Curriculum Planner Module & 370 & 75 & 5 \\
\hline Curriculum Modelling Module & 367 & 78 & 5 \\
\hline Development Planner Module & 365 & 80 & 5 \\
\hline EMS Transfer Module & 364 & 81 & 5 \\
\hline Library Module & 370 & 75 & 5 \\
\hline Equipment Register Module & 402 & 43 & 5 \\
\hline
\end{tabular}

*1=everyday, $2=$ every week, $3=$ every month, $4=$ few times a year, $5=$ never

The results showed that STAR had the highest overall use, particularly by Clerical and Deputy Head respondents which was to be expected since it is the core database of the SIMS system. MIDAS was the next most widely used module, this time by Deputy Heads and Heads. Alert and Development Planner were the least used modules overall.

The respondents with a clerical role in the organisation reported after STAR, the Report Generator followed by MIDAS, Timetable, Attendance and Options were the modules they used most commonly. Deputy Heads used STAR, MIDAS and Timetable (probably for planning cover) most frequently, as did SIMS Managers used who used STAR, MIDAS, Timetable and in addition, FMS. Office Managers used STAR, FMS and 
Personnel; Head Teachers used STAR, MIDAS Timetable and Attendance. Some module use was unexpected. For example, according to the LEAs, 'Attendance' is run on a daily basis in every High School in Staffordshire and Derby. An overall result close to $100 \%$ use could be expected. However, since use of SIMS is spread across many different people in the organisation, the people responding to the questionnaire would not necessarily have high individual use.

\subsection{SIMS use in previous case studies}

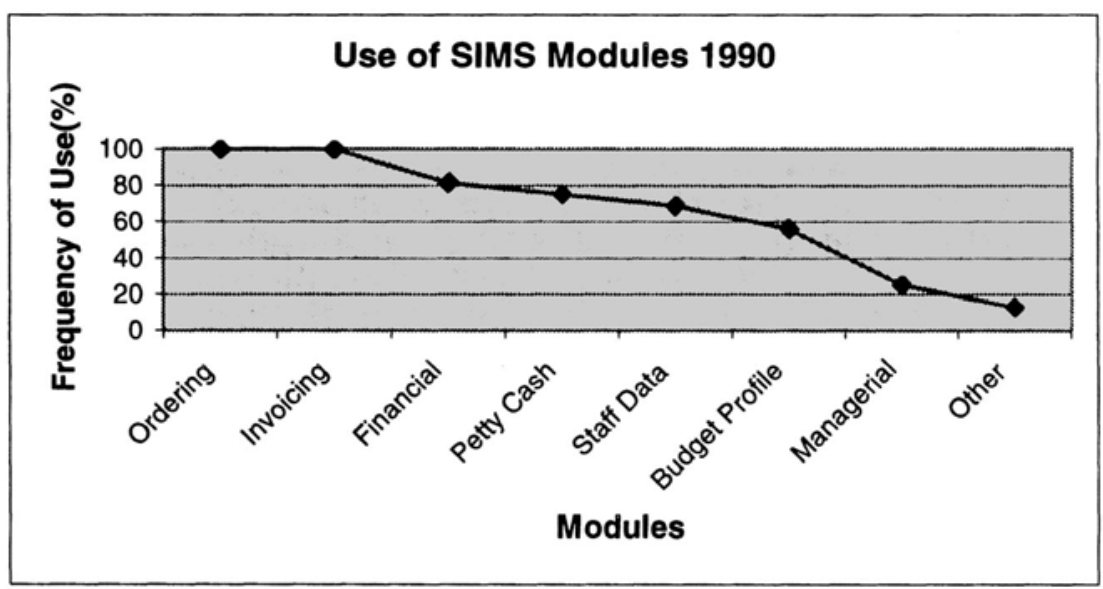

Figure 2. Direct use of SIMS modules in the 1990 case study

In 1990, the primary use of SIMS was for inventory (ordering and invoicing) and financial applications, a direct result of the delegated budget demands imposed on schools at the time. The range of modules was very limited compared to the current implementation of the software and many schools were reported as having insufficient data transferred to electromagnetic medium from hard copy to make much old data usable in the system. Problems related to job design and organisational issues were also reported as barriers to the wider use of some of the modules. 


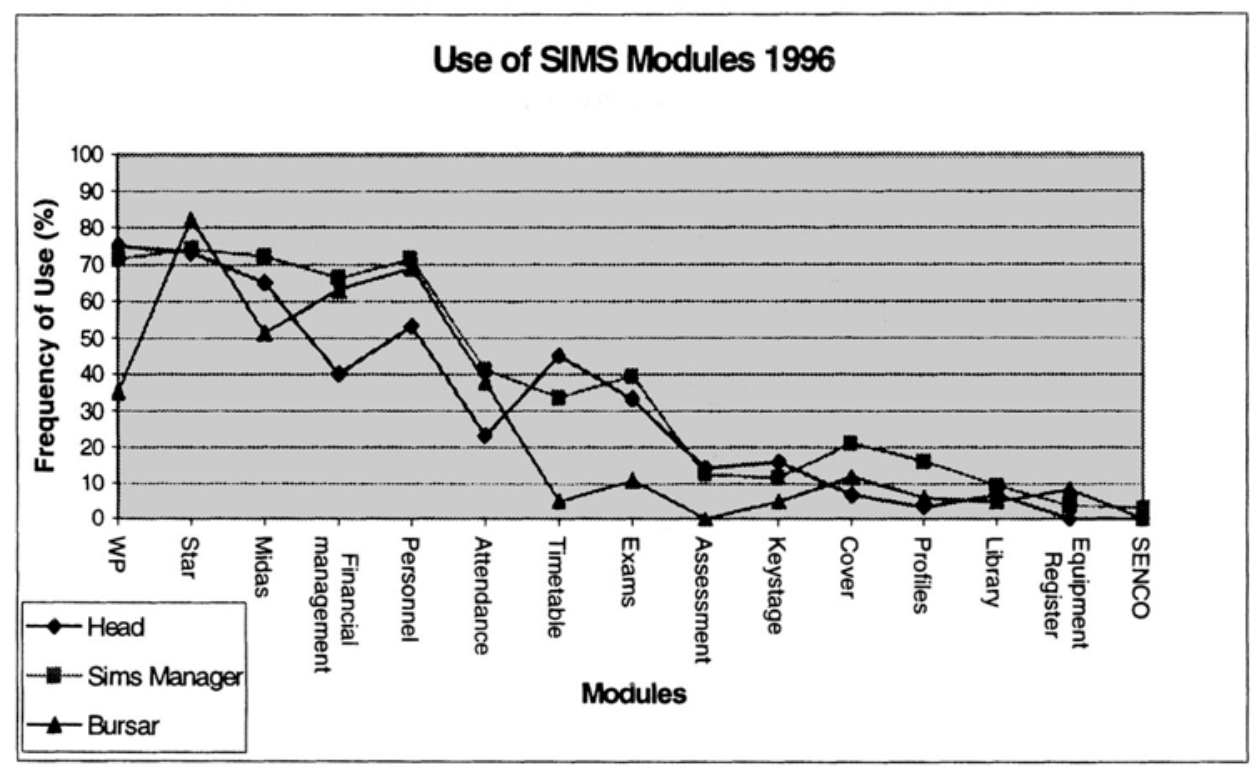

Figure 3. Direct use of SIMS modules in the 1996 case study

In this study Star, Midas and Financial Management modules are at the top of the list of frequently used modules across all users. The Head teachers used the Personnel and Timetable Modules more than the Financial Management package, which was primarily the area used by the SIMS Manager and the Bursar. The latter's use centred on Star, MIDAS, FMS and Personnel and was similar although more restricted than the usage patterns of the SIMS Manager.

The usage patterns for the modules that existed in both later studies were remarkably similar in emphasis despite the substantial increase in modules available (8 main modules in 1990, 15 in 1996, 28 in 1999), and an apparent shift in emphasis in school administration tasks over the period.

\subsection{Number of hours spent per week using SIMS}

In 1990 the time spent by staff working directly on SIMS rather than with its processed data was estimated at between 11-20 hours per week (see Table 2). In 1999, direct use of SIMS averaged 5-10 hours across all categories of user (see Table 3). 
Table 2. Average number of hours spent using SIMS (1996)

$\begin{array}{lrc}1996 & \begin{array}{c}\text { Hours perweek } \\ \text { Direct use }\end{array} & \begin{array}{c}\text { Hours per week } \\ \text { Indirect use }\end{array} \\ \text { Headteacher } & 1 & 5-10 \\ \text { SIMSAdmin } & 21-30 & 5-10 \\ \text { Teacher } & 5-10 & 1-4 \\ \text { Bursar } & >30 & 5-10 \\ \text { Average } & \mathbf{1 1 - 2 0} & \mathbf{5 - 1 0}\end{array}$

Table 3. Average number of hours spent using SIMS (1999)

$\begin{array}{lcc}1999 & \begin{array}{c}\text { Hours per week } \\ \text { Direct use }\end{array} & \begin{array}{c}\text { Hours per week } \\ \text { Indirect use }\end{array} \\ \text { Clerical } & 11-20 & 1-4 \\ \text { Teacher } & 5-10 & 1 \\ \text { Deputy Head } & 1-4 & 1-4 \\ \text { Head } & 1 & 1-4 \\ \text { SIMS Man } & 5-10 & 1-4 \\ \text { Average } & \mathbf{5 - 1 0} & \mathbf{1 - 4}\end{array}$

In the two later studies all respondents used SIMS directly while in the first study a number of head teachers did not have any hands-on system use.

The workload in terms of weekly use has clearly altered since the introduction of SIMS in 1990. It appears that the work patterns of staff involved with data processing in schools has changed and that those with a managerial role are now more involved in hands-on work with the system than at the outset of the study. The workload is more dispersed in the 1999 study, perhaps reflecting the wider use of networked systems creating greater staff access. Also likely is the wider range of modules in use supporting managerial functions resulting in broader use by school management.

\subsection{Workload and stress using SIMS compared to previous systems}

At the beginning of the study direct end-users were much more of the opinion that SIMS increased stress and workload. Later, when the use of computer systems in the work environment was better established and system management was more effective, users considered the workload and stress imposed by using the system was less than in earlier studies. Users' workload and stress assessments in 1996 are shown in Figure 4 and in 1999 in Figure 5. 


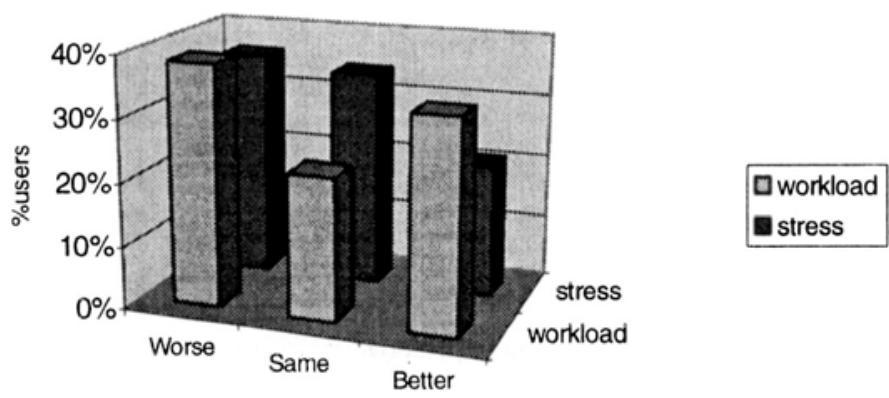

Figure 4. Workload and stress levels using SIMS (1996)

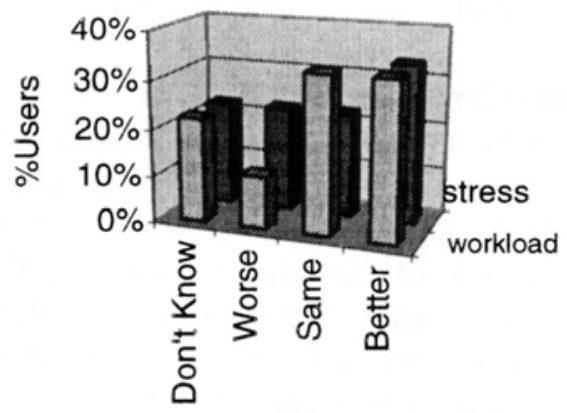

Figure 5. Workload and stress levels using SIMS (1999)

Workload was reported as lower in the 1999 study despite the fact that more data was being processed than in 1996, because the workload was dispersed among more staff, including those whose job was specifically designated as being responsible for the automated administration of the school. Stress levels have reduced probably because people are more comfortable with the computer system than in previous studies. There is a 'don't know' category in the 1999 study because some respondents had not used any other system than SIMS so could not compare workload or stress with previous systems they had used. 


\subsection{Modules used in making management decisions}

In the 1990 study, the modules reported as being used most frequently by respondents in management were Financial Summary and Budget Profiles.

In the 1996 study, the modules most frequently cited as being used to assist in making management decisions were Star, Financial Management System, Midas, Timetable, Personnel and Attendance modules (55-89\% of the sample) (see Figure 6).

\section{SIMS Modules Used for Management Decisions 1996}

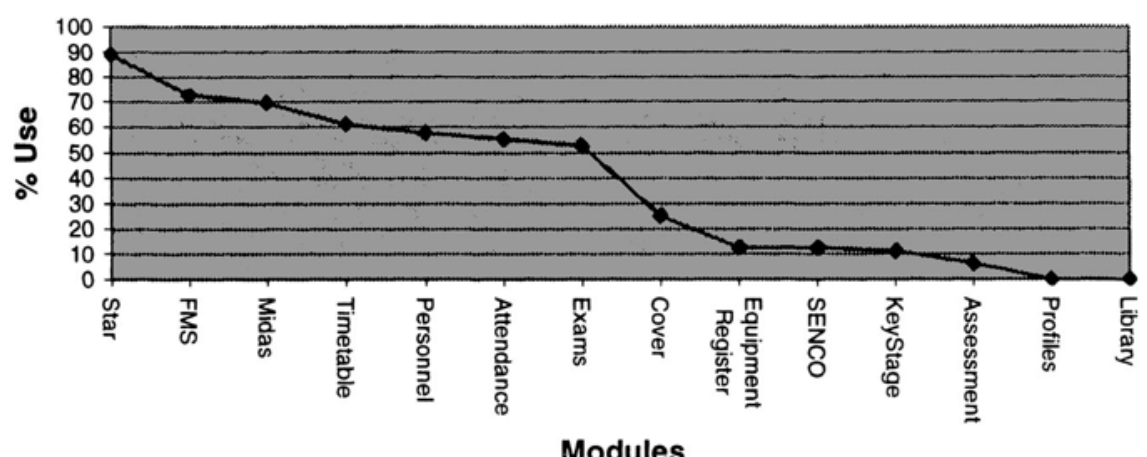

Figure 6. SIMS modules used for management decisions (1996)

In the 1999 study, the modules most commonly used as a source of management information (68-81\% of the sample) used by the Head Teachers, Deputy Heads and Principals were as follows: Financial Management System (FMS), MIDAS (Data Analysis), STAR (Core system module), Timetable, Attendance and Personnel. 


\section{SIMSModuleUseforManagementDecisions 1999}

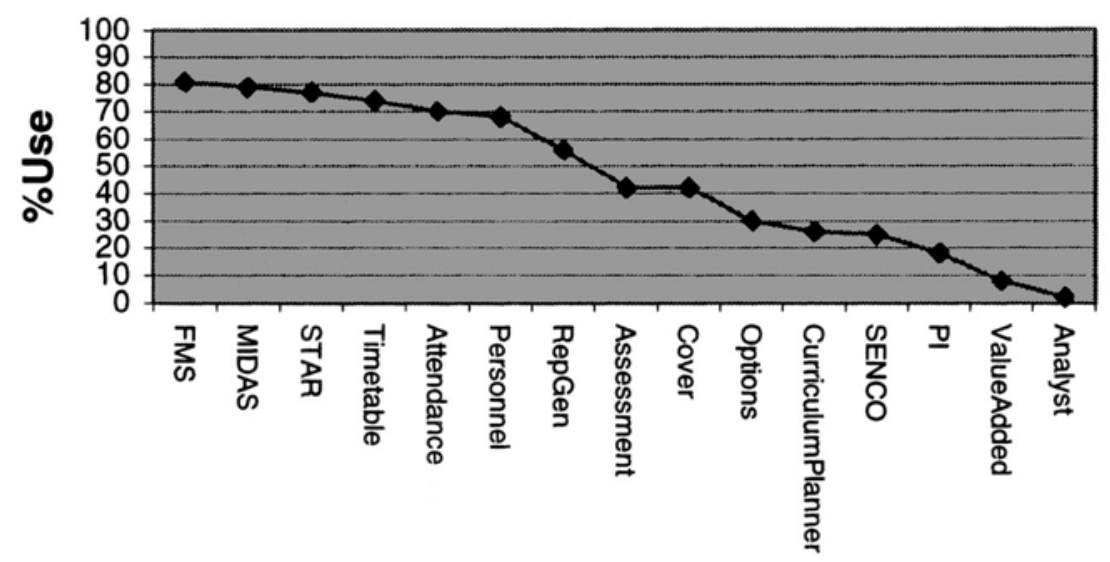

Modules

Figure 7. SIMS modules used for management decisions (1999)

The SIMS modules used in a managerial context to assist in decision-making differed from those used on a general day-to day basis by non-managerial staff. TheFinancial Management and MIDAS modules were the most widely used modules. STAR, Timetable, Attendance and Personnel were the next most frequently used modules. The Assessment and Cover modules were also quite frequently used in this context. An anomaly occurs in the results for the Performance Indicator Module that provides compulsory external returns for exams and attendance. When investigated further, it was found that several schools used spreadsheets such as MSExcel which were used in preference to the SIMS software module to make their returns.

The importance of Financial Management in management decisionmaking is still largely unchanged across the decade, but a much wider range of modules are now being employed by managers. This is probably due to the availability of additional information from new modules and the legislative pressure to consider these data.

\subsection{Respondents' experience using computers}

The increase in user's home computing experience was approximately $10 \%$ over the three year period from 1996-1999, and 7\% at work (Table 4). There were no figures available for 1990, but we can assume that experience of 
using computers was lower since overall PC ownership in 1990 was much lower than in 1996. In 1998 a survey found that, in the US, $50.3 \%$ of households in the country owned a PC. The number of households buying a computer during the year rose 5.5\% from 1997, figures not dissimilar to those for our UK school staff home computer use (NUA Internet Surveys, 1998).

Table 4. Experience using computers

$\begin{array}{lcc} & \begin{array}{c}\text { Home } \\ \text { Experience }\end{array} & \begin{array}{c}\text { Work } \\ \text { Experience }\end{array} \\ \begin{array}{l}1996 \% \text { respondents } \\ \text { with some ormuch } \\ \text { experience }\end{array} & 44 \% & 55.8 \% \\ \begin{array}{l}1999 \% \text { respondents } \\ \text { withsome ormuch } \\ \text { experience }\end{array} & 54.4 \% & 62.8 \% \\ \end{array}$

Users have clearly become more experienced and sophisticated over the decade due to their increased exposure to information technology. This has increased their expectations of all aspects of computer systems ranging from the look and feel to system functionality and task fulfilment.

\subsection{System quality}

Users in the 1999 study were questioned on various aspects of system quality. The majority were happy/very happy with the hardware performance compared to previous system use. According to $90 \%$ of respondents, the system usually or always worked reliably, but $70 \%$ were unhappy with their working environment, mainly due to interruptions. When asked to compare the data quality with that of the previous systems, $49 \%$ said only some/a little of the material provided by SIMS was relevant and $49 \%$ said most/all of information was relevant. Data Currency was found to be better or much better by $73 \%$. Data Completeness was found to be better or much better by $59.8 \%, 8.6 \%$ found it worse and $27.7 \%$ the same.

\subsection{Training in system use}

In 1999 the majority of external training was by the LEAs (68\%), 20\% were trained directly by SIMS and the rest did not reply to the question. Internal training was received by $90 \%$ of respondents, but the duration of this training was limited (Table 5). This compared closely to the training received by respondents in the two previous case studies. 
Table5. Average hours of training (1999)

$\begin{array}{lcc} & \text { Internal } & \text { External } \\ <1 \mathrm{hr} & 53 \% & 11 \% \\ 1-4 \mathrm{hrs} & 28 \% & 23 \% \\ 510 \mathrm{hrs} & 11 \% & 19 \% \\ 11-30 \mathrm{hrs} & 5.9 \% & 14 \% \\ <30 \mathrm{hrs} & 2 \% & 24 \%\end{array}$

Fifty six percent of the respondents were neutral, unhappy or very unhappy with the amount of external training. However, 63\% were happy or very happy with the quality of the training they did receive.

\subsection{Access to help}

Getting help from within the school was found to be easy or very easy by $48 \%$ of the sample. Thirty two percent found it hard or very hard to get help outside the school from LEA or SIMS help desks.

\subsection{Levels of user satisfaction}

When average variable scores for levels of user satisfaction were investigated, a number fell below neutral on a 1-5 normalised scale ( 5 being the most positive user response, 1 the least).

In the 1999 study below neutral scores were obtained for working environment, training (internal and external), problem solving, user interface issues, comparison with previous systems (planning and communication), the amount of time spent on the system and the users' computing experience.

The amount of external training received and the quality of external training were the most significant variables in this study and showed the highest variance across user roles. Twelve other variables gave significant results, of which nine were related to user interface of the SIMS system, two to problem solving and use of help lines, and one to the effect of SIMS on school management.

In the 1990 study the differences between users' roles and their perception of the system were accentuated much more strongly. The user interface aspects of the system and comparison with previous systems used producing the lowest scores.

In 1996 comparison with previous system scores had improved and showed less significant difference between roles. 


\subsection{Users' comments}

In 1990, the majority of direct SIMS users said that rather than saving time, SIMS wasted time because of its 'unforgiving and rigid nature'. The indirect users who all held managerial roles were much more positive about SIMS and felt that the school could not operate without a computerised administration system which they felt would become an effective management tool in the future. They mostly anticipated using the system themselves rather than relying on clerical staff to provide them with results.

In 1996 a summary of respondents' comments suggested that the biggest problem people were having was with the Report Generator module - it was too complicated and not flexible enough, making it difficult to define queries and printouts. It resulted in an inability to produce reports from various modules. The majority of users wanted a Windows environment for all modules including Report Generator.

The general feeling was that SIMS was a good system, and they had not found a better one. However, most people felt that the system needed fine tuning, that it had bugs and that they were always waiting for upgrades to sort out problems. They also said that the quality of SIMS varied greatly between modules.

In 1999 a few ofthe salient points that appeared in users' comments were that SIMS had made an invaluable contribution to administration efficiency. Again there were some provisos including that the cost of updating and maintaining SIMS was a problem. Some SIMS modules were not well quality controlled before shipping and SIMS needed to keep pace with developments in education and speed its updating of modules to Windows. It needed more flexibility in all modules, particularly in user assigned fields, and more presentation options, e.g. font styles. Report Generator was no longer a major cause of complaint since it had been rewritten for Windows.

\section{CONCLUSIONS}

\subsection{The changing role of the information system in educational organisations}

Schools have not up to now had to work under the same pressures as industry. They have always had tight budgets and different priorities from commercial organisations. It is not easy to assess cost effectiveness in an educational environment, and investment in technology was not a priority until it was forced on schools by legislation. In late 1980s, the National 
Curriculum was introduced for which computer support was unavoidable. Subsequently legal requirements, such as child monitoring, Form 7 returns and external assessments, all mean that secondary schools now have to accept their commitment to IT systems to perform these tasks. At the start of our study, some schools clearly did not adopt the development ethos and were not prepared to make continuing investment in IT after the initial funding was given. Schools were not educated to spend money on technology and after the initial external investment, many just sat on the assets and made no further investment in IT. As the study progressed however, the pressure on schools to handle data effectively and produce feedback to outside agencies has steadily increased, as has the volume of data they have had to handle. This has made the use of computerised systems indispensable and forced them to change their modus operandi. In particular, pressure from UK legislative requirements detailed in the latest Government Green Paper on Education will shortly require that teachers use information such as that input into SIMS to establish pupil progress in order to assess performance related pay for teachers.

\subsection{Changes in system use and perception over the decade}

In the first study in 1990, the managers tended not to be the end users of the computerised systems. As in other industries at that time, they still regarded keyboarding tasks as the role of the clerical staff. Because they only used the processed data and not the system directly and were happy with the information they were getting, they did not have any objections to what was then a relatively user unfriendly system. As the decade progressed and managerial styles changed in the educational organisation to become more devolved and by necessity more hands-on, the views of these users changed to become more discriminatory. The clerical staff still tend to be the primary users of STAR and MIDAS modules, but managerial staff and system managers are now using a wide range of modules directly. In addition there are now staff in many schools whose role is partially or wholly dedicated to the task of system management and data processing.

\subsection{User requirements and system functionality}

From the outset of studies of School Information Systems, it has been a criticism that commercial systems that have been developed for use in schools have fundamental problems in limited functionality and inflexibility (Wild and Fung, 1996).

In the early study the SIMS system did not map well onto the user tasks being performed manually and the users did not perceive the system as being 
useful. However, it appears that in both later studies, improvements to the system and increasing adaptability of users have resulted in the users' opinions of the system improving.

\subsection{The survey population}

In the 1990 case study it was easier to define users and non-direct users. Management did not see their role as a hands-on one in data processing. However, today as management decisions have become more devolved to a management team, as in any large organisation, it is more difficult to identify the right people to ask the appropriate questions.

It is becoming clear from the data collected that the respondents' view of SIMS is dependent on the Local Support Unit in the LEA. If the unit is effective and in particular their training programs are effective, the users' views tend to be much more positive than when the unit is of low quality. This data has yet to be analysed from the main survey.

The software is no longer novel and the users do not feel that their answers will influence the software developers in any way, particularly since the product has virtually a market monopoly in England.

\subsection{Summary}

The results from these studies showed an overall improvement of data handling operations in schools using SIMS. Many areas of administration have been delineated and clarified as a result of using a computerised information system. However it is one thing to have the data and another to process it effectively and use it as a source of information. The initial stages of our study suggest that these processing tools are reasonably comprehensively available in SIMS but are not necessarily being used by schools.

\subsection{Further analysis}

We need to consider the variables that impact on our results, including the availability of resources in different schools and whether or not the technology introduced was appropriate for the institution. We would like to define good and bad practice in management and administration using computerised school information systems such as SIMS. And we need to look at the managerial and non-managerial roles of individuals in the school organisation in more detail. 
We intend that further analysis of results will provide categorisation of schools by their effectiveness as Information Handlers and will indicate why some institutions are more successful than others in this respect.

\section{REFERENCES}

Scivier, J.E. (1990). A user acceptability evaluation of a computerised administration system in secondary schools (MSc Dissertation). Loughborough: Loughborough University.

Visscher, A.J. (Ed.). (1996). Information technology in educational management. International Journal of Educational Research, 25 (4), 289-390.

Visscher, A.J., \& Bloemen, P.P.M. (1999). Evaluation and use of computer-assisted management information systems in Dutch schools. Journal of Research on Computing in Education, 32 (1), 172-188.

Wild, P., \& Fung, A. (1996). Evaluation of information technology in educational management for proactive development. Education and Information Technologies, I, 239249.

Wild, P., Scivier, J.E., \& Richardson, S.J. (1992). Evaluating information technologysupported local management for schools: The user acceptability audit. Educational Management and Administration, 20 (1), 40-48.

Department for Education and Employment, (1998). Education Green Paper. London: HMSO.

(1998). PC ownership in the US. NUA Internet Surveys, 4 (11). 